\title{
Recreation Features Inventory in Sri Lanka: With Special References to Ambewela-Idalgashinna Railway
}

\author{
Chamila Priyadarshani Wijethissa and Dulika Priyangani \\ Department of Sport Science and Physical Education, University of Kelaniya, Sri Lanka
}

\begin{abstract}
The main purpose of study was to innovate recreation features along the Ambewela to Idalgashinna railway road with railway recreation. There were four objectives in this study. In this context, RFI (Recreational Features Inventory) database is used to collect data classification when and where certain observations were made to collect respective primary data. The data was collected for the study via RFI data collecting which consisted of most suitable questions and variables. In this study, the data sample method was the purposive sample method and the research limited to four railways stations. The data analyzed form GIS (Geographical Information System), Google map and matrix. There were 14 tunnels between Ohiya to Idalgashinna. There is a large number of tunnels between two stations in the world and there are 18 tunnels in the whole research area. The researcher could identify the growth of recreational features from Ambewela to Idalgashinna. In addition, the researcher identified natural resources for the tourism industry and $70 \%$ sensitive and 30\% none-sensitive recreational features from Ambewela to Idalgashinna research area. The GIS map indicated the growth patterns of particular recreational features in this area.
\end{abstract}

Key words: Recreation, railway, GIS, features.

\section{Introduction}

Recreations are usually undertaken in free time and produced wellbeing fulfillment, enjoyment, relaxation and satisfaction. The recreation can be mainly divided into two categories: active or passive and indoor or outdoor. Recreation opportunities are one of the major foreign exchange earners and major growth sector for many countries, especially the small islands which are rich with required natural and culture resources. There are many researches which are based on railway road and recreation in the world whereas such studies are not given priority in Sri Lanka. The purpose of the study was to make people aware of the necessity of recreational opportunities. According to the recreation features inventory production and standards manual, there was a recommended recreation inventory called RRI (recreation resource inventory).

In Fig. 1, some of these component inventories may contain many detailed inventories, as required for input

Corresponding author: Chamila Priyadarshani Wijethissa, lecturer, research field: sport and recreation management. into planning and/or operational initiatives. For example, the RFI is currently complemented by three other detailed inventories: Trails and Routes, River Recreation and Caves. These three inventories provide more specific information on these recreation resources. The other component inventories may provide additional information to the RFI and/or a context for rating feature significance and sensitivity, as follows.

When considering above background, the researcher assumes that specific railway recreation culture can be identified in Sri Lanka. So as to develop the recreation culture, a recreation feature inventory must be conducted as the first step. Therefore, the researcher has conducted the recreation features inventory with special reference to Sri Lankan railway stations situated from Ambewela to Idaigashinna.

This study was carried out to achieve the following objectives, which were already divided in to two categories as the key objective and specific objectives. The key objective was to delineate recreation feature inventory and the specific objectives were to identify Administrative Information in the study area, to delineate 


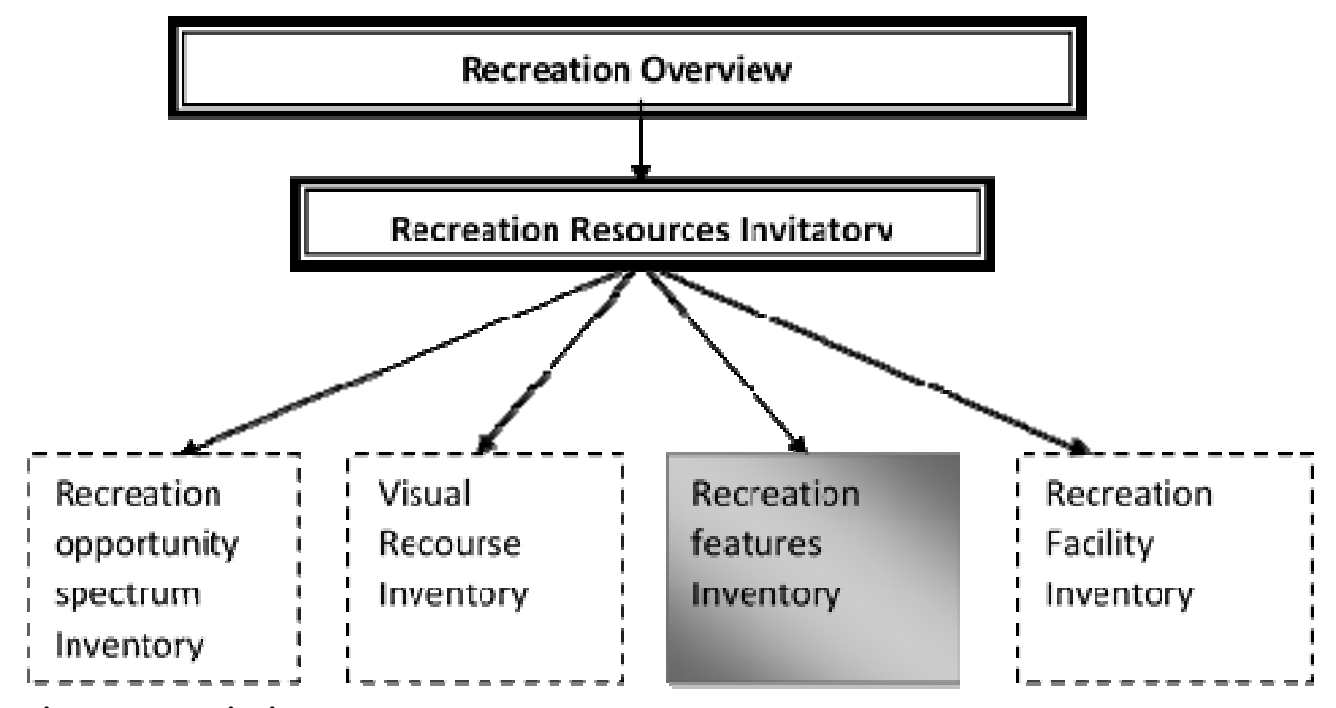

Fig. 1 Recreation resources invitatory.

(Source: Recreation Recourse Inventory Manual, 1998, Conducted by Researcher 2013).

recreation feature and activities in railway polygon, to delineate significance and sensitivity in recreation feature and railway polygon, and to identify photographic point data recreation features.

\section{Literature Review}

Recreation is an emotional condition within an individual human being that flows from a feeling of well-being and satisfaction. It is characterized by feelings of mastery, achievement, exhilaration, acceptance, success, personal worth and pleasure. It reinforces a positive self-image. Recreation is a response to aesthetic experience, achievement of a person's goals, or positive feedback from others. It is independent of activity, leisure or social acceptance [1]. Recreation is a worthwhile socially acceptable leisure experience providing immediate, inherent satisfaction of the individual who voluntarily participate in activity [2].

A recreation opportunity is the availability of choice for someone to participate in a preferred recreation activity within a preferred setting and enjoy the desired experience. The purpose of the Recreation Opportunity Spectrum (ROS) Inventory is to identify, delineate, classify and record areas within the province into recreation opportunity classes based on their current state of remoteness, naturalness and expected social experience. The recreation database includes information on types of features at a site such as beach, small creek or stream, historic features, harbor features (i.e. anchorage or boat launch), and human-made features (e.g. developed or undeveloped campsite). Recreational activities are also recorded in the database. Activities can vary from water sport activities such as kayaking, scuba diving or swimming, to fishing activities (e.g. freshwater sport fishing or shell fishing), camping activities, motorized boating activities and viewing activities. Up to eight features or activities can be recorded for each site. Professional judgment was used to determine the key or primary feature and activity at each site. The Recreation Features Inventory states: "Scenic uplands and highly attractive alpine areas are a major attraction of the area. Of particular significance are large areas of rolling alpine terrain distributed throughout the Boundary Ranges. They offer good opportunities for hiking, wilderness travel, nature appreciation and wildlife viewing. These areas provide access to areas of more rugged terrain containing dramatic scenic features. Consequently, there are excellent opportunities to view small glaciers, rock glaciers, distinctive peaks, cirques, alpine lakes, and tarns" [3]. 


\section{Methodology}

As this study is exploratory in nature, it was intended to collect primary data as much as possible. In this context, a RFI database and GIS map used to collect data classification when and where, certain observations were also made to collect respective primary data. The Data was collected for the study via RFI data collecting which consisted of most suitable questions and variables. In this study, the sample method was purposive sample method. In Sri Lankan context, the most beautiful railway is the Upcountry railway road and there were very significant recreation features in this railway road. For presenting the data, the researcher used GIS map, graphs and tabulations and for the purpose of data analysis, polygon delineation was used. The data analysis form GIS and Google map. This method was GIS dependent. Polygon-based analysis has the advantage of capturing the full extent of channel changes and utilizing the automated functions available in GIS. Fieldwork was the process of validating preliminary information and public input by checking polygons on the railway. In general, as a rough provincial standard, approximately $5 \%$ of the Recreation Features (RF) should be visited in the field. The criteria for determining how much fieldwork is to be done and which polygons will be field checked. The Researcher used Recreation features Inventory production and standards manual report for data collection and Analysis. Some factors changed according to the objective to the research. Therefore new RF corded was added to the research.

After identifying the recreation features in the particular sample, the researcher analyzed the significance level and sensitivity level of each polygene according to the RFI manual. In this sense, the researcher used six factors for measure significance and ten factors for sensitivity. The significance factors were: (1) activity attraction capability; (2) uniqueness; (3) scarcity; (4) scenic view; (5) amount of current recreation use; and (6) accessibility. The sensitivity factors were: (1) timber harvest openings; (2) transportation routes (road, rail, and airfields); (3) power, seismic or pipeline corridors; (4) mining, quarries, gravel pits, dumps; (5) structural (bridges, buildings, docks and floats); (6) agricultural developments; (7) settlements; (8) recreation use areas (ski hills, sites and trails); (9) aquaculture developments; and (10) other types of alteration (record type in the statement of rationale).

\section{Results}

Table 1 shows 1 cultural feature, 3 water body features, 2 travel route or trail features and 2 human-made features in the Ambewela railway polygon. It presents $12 \%$ cultural features, 38\% water body features, 25\% travel route or trail features and 25\% vegetation features in the Ambewela railway polygon.

In Ambewela to Pattipola railway line, the researcher found out several recreation features like 1 cultural feature, 3 vegetation features, 3 travel route or trail features, and 1 cave/karts feature. It presents 12\% cultural features, 38\% travel route or trail features, 37\% vegetation features, and $13 \%$ cave/karts feature in the Ambewela to pattipola railway line.

Table 1 The percentage features in sample area.

\begin{tabular}{lllll}
\hline & Ambewela railway polygon & Ambewela to Pattipola & Pattipola to Ohiya & Ohiya to Idalgashinna \\
\hline Cultural features & $12 \%$ & $12 \%$ & $14 \%$ & $3 \%$ \\
Historical features & 0 & 0 & 0 & $4 \%$ \\
Vegetation features & $25 \%$ & $37 \%$ & $29 \%$ & $11 \%$ \\
Water body features & $38 \%$ & 0 & 0 & $18 \%$ \\
Generic landform features & 0 & $13 \%$ & $14 \%$ & $11 \%$ \\
Travel route or trail features & $25 \%$ & $38 \%$ & $43 \%$ & $53 \%$ \\
\hline
\end{tabular}

(Source: survey data 2013). 


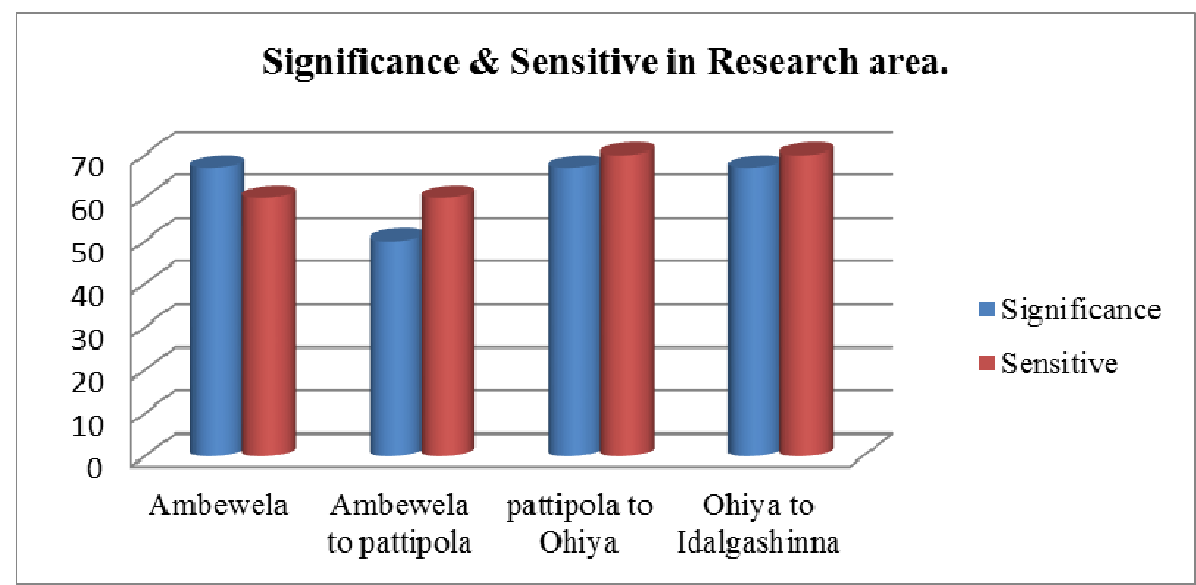

Fig. 2 Significances and sensitive of recreation polygon.

(Source: survey data 2013).

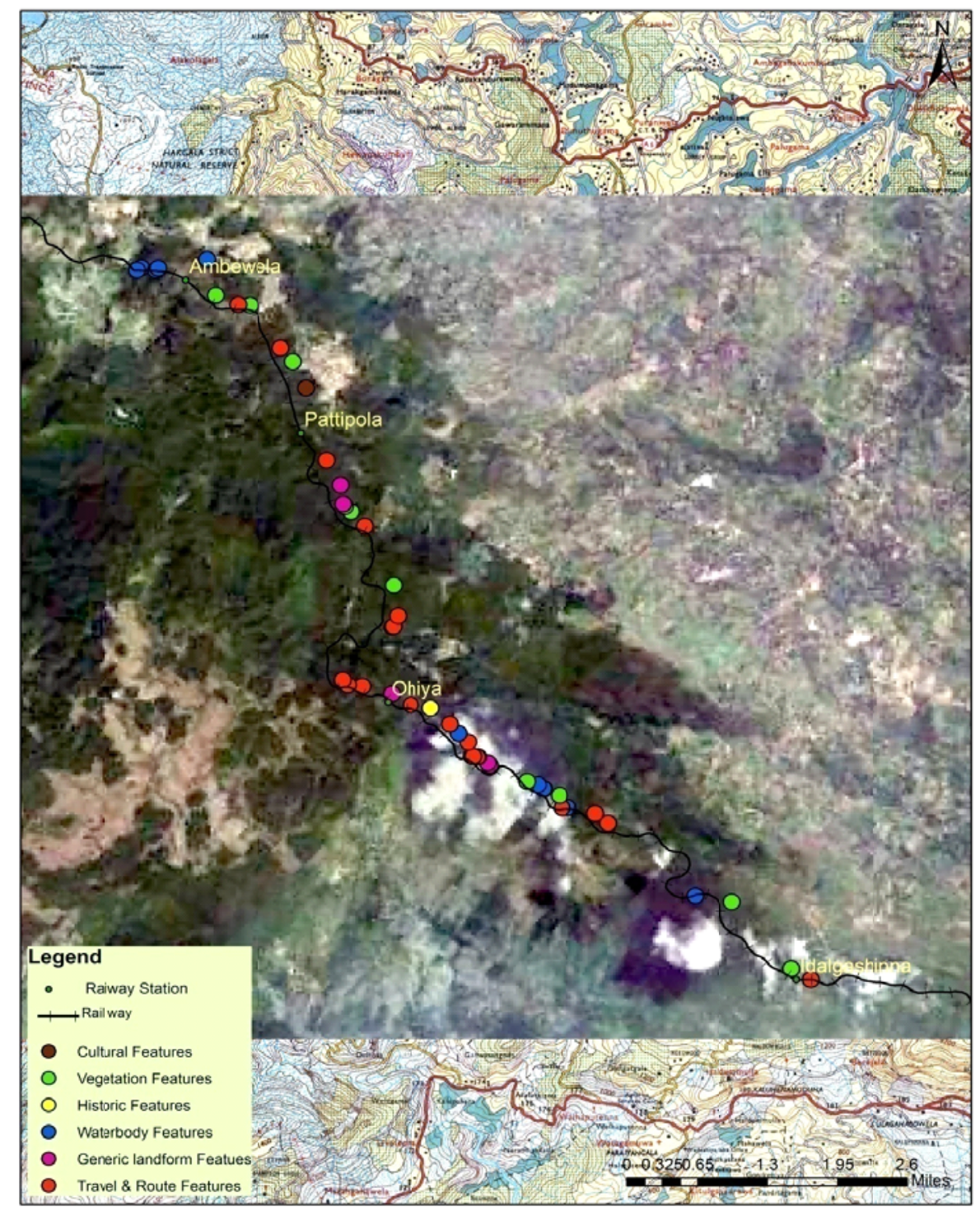

Fig. 3 Rail way recreation features inventory map.

(Source: survey data 2013). 
Included $7 \mathrm{~km}$ in Pattipola to Ohiya railway line, there were 2 cultural features, 4 vegetation features, 6 travel route or trail features, and 2 generic landform features in the particular polygon.

Included $8.5 \mathrm{~km}$ Ohiya to Idalgashinna railway line, there are 14 tunnels between Ohiya to Idalgashinna. This is the most number of tunnels between two stations in the world. According to survey data, 1 cultural feature, 1 historic feature, 3 vegetation features, 5 water body features, 15 travel route or trail features, and 3 Generic landform features. It presents $14 \%$ cultural features, $43 \%$ travel route or trail features, 29\% vegetation features, and 14\% generic landform features in the Pattipola and Ohiya railway line.

Fig. 2 shows the significance and sensitive capacity of recreation polygons that researcher selected. According to this, there were four polygons in this area. There were three polygons took more than $70 \%$ of significance and sensitive capacity in this area and Ambewela to pattipola polygon has been shown 57\% for significance capacity and $67 \%$ for sensitive.

Fig. 3 shows recreation features and how those features located in particular sample area. In this context, most of features were located in the area between Ohiya and Idalgashinna. There are limited numbers of cultural features in this area and there are many travel and route features in this area.

\section{Conclusion}

The findings are based on the delineate recreation features and recreation activities in railway line. The researcher identified the growth of the recreation features, high significance and sensitive recreation feature and activates from Ambewela to Idalgashinna. According to the findings, there are $60 \%$ of sensitive features and $70 \%$ of significance features in this particular research area. The researcher builds a GIS map based on the related information in the research. There was a limited cultural feature in the research area. There are lots of features in travel and route features in research area. There are minimum recreation features located near the Idalgashinna. There are maximum recreation features located near the Ohiya station. The GIS map is the most important thing that was used for identifying recreation features in the research area.

\section{Recommendations and Suggestions}

New programmmes can be introduced for the development of the tourism industry by the government and the railway department. Moreover, those who are interested in the same field can continue their research on recreation features in the stations between Idalgahinna and Badulla in the upcountry railway line.

\section{References}

[1] Gray, D., and Pelegrino, D. 1973. Reflections on the Park and Recreation Movement. Dubuque, Iowa, William C. Brown, 7.

[2] Daniel, M. D., and Hurd, A. 2011. Kraus' Recreation and Leisure in Modern Society: Basic Concepts of Play. Burlington: Jones \& Bartlett Publishers NO 24, 47.

[3] Loeks, D. 2008. Recreation and Tourism Assessment. Recreation and Tourism Assessment. Whitehorse, Yukon Parks, Department of the Environment. 